\title{
Can a Blockchain-Based Maas Create Business Value? ${ }^{\dagger}$
}

\author{
Gabriel Hogan ${ }^{1}$, Sigma Dolins ${ }^{2}$, Izzet Fatih Senturk ${ }^{3, *}$, Ioannis Fyrogenis 4,*, Qian Fu 5 , \\ Erion Murati ${ }^{6}$, Federico Costantini ${ }^{7}$ and Nikolas Thomopoulos $8, *$ \\ 1 ADAPT Centre, Dublin City University, D09 Dublin, Ireland; gabriel.hogan8@mail.dcu.ie \\ 2 Division of Design \& Human Factors, Department of Industrial and Materials Science, \\ Chalmers University of Technology, 41296 Gothenburg, Sweden; dolins@ri.se \\ 3 Department Computer Engineering, Bursa Technical University, 16310 Bursa, Turkey \\ 4 School of Civil Engineering, Aristotle University of Thessaloniki, 54124 Thessaloniki, Greece \\ 5 School of Engineering, University of Birmingham, Birmingham B15 2SA, UK; q.fu@bham.ac.uk \\ 6 Law Faculty, University of Hamburg, 20148 Hamburg, Germany; erion.murati@studium.uni-hamburg.de \\ 7 Department of Law, University of Udine, 33100 Udine, Italy; federico.costantini@uniud.it \\ 8 WISE-ACT and Department of Tourism \& Transport, University of Surrey, Guildford GU2 7HX, UK \\ * Correspondence: izzet.senturk@btu.edu.tr (I.F.S.); fyrogeni@civil.auth.gr (I.F.); chair@wise-act.eu (N.T.) \\ + Presented at the 3rd annual Decentralized Conference, Athens, Greece, 30 October-1 November 2019.
}

Published: 17 October 2019

\begin{abstract}
In this paper two contemporary technological novelties are combined to introduce the concept of a blockchain-based MaaS, with the aim of pinpointing where and how business value can be created through data-based services of such a system. Towards this purpose, an integrated version of the Business Model Canvas is deployed, combining the advantages of the Lean Canvas and the Ethics Canvas. The overview of data flows among the versatile system stakeholders are outlined to highlight the potential benefits for diverse industries through sharing and collaboration.
\end{abstract}

Keywords: MaaS; blockchain; business value; Business Model Canvas

\section{Introduction}

Artificial intelligence, Automated and Connected Vehicles, Distributed Ledger Technology(DLT), cloud computing, 3D printing are disruptive innovations, already introducing societal and business transformations [1]. Distributed Ledger Technology (DLT) is the established term in the literature, whereas Blockchain is a widely used term covering certain aspects of DLT. DLT is used in this paper as an encompassing term, although specific links with Blockchain are highlighted in (e.g., Section 3 [2]). Although it is still uncertain how they will impact everyday life, it is very likely that their effect on shaping future societies will be enduring.

Many of these innovations are entwined with the increasingly important role of transport. Contemporary projections anticipate smart urban mobility revolutionizing all modes of passenger and freight transport [3]. Connected vehicles may become the norm and essentially would be a new communication medium, whether public, private, individually owned or shared. Data is at the heart of this revolution, since it is considered the new currency of the 21st century [4,5]. Each connected car is anticipated to generate the same amount of data as 2600 individual broadband internet users [6]. Therefore, the main challenge is harvesting personal data generated by drivers, passengers, pedestrians, cyclists in aggregate form to create additional value. DLTs in particular, provide the potential for a scalable transaction capability that provides transparency, traceability and control to individuals and organizations with respect to their harvested data in the connected transport ecosystem.

Technological advancement now allows the generation and collection of personal data at both an individual and aggregate level. Despite the potential data and cybersecurity risks, DLT is 
facilitating such innovation and it forms the foundation of this paper. The focus is on using DLT, and blockchain in particular, to facilitate a Mobility-as-a-Service (MaaS) system as the transaction repository mechanism. This position paper is therefore concentrated in business value creation through MaaS data using a permission based DLT.

\section{Background and Key Notions}

Good decisions are worthwhile with 'high outcome benefits' and worth the cost having 'low outcome costs' [7]. Given current urbanization and population growth projections [8], it is essential to address the negative externalities of the transport sector. Up to 60 hours per person per year can be saved through smart mobility [3]. Compact urban development and smart urban mobility feature as prominent solutions to ensure improved wellbeing and sustainable resource use [9-11]. On the other hand, MaaS promises to address this challenge through shared and integrated mobility [12]. A key component of the MaaS business use case is its connected infrastructure, which enables the leveraging of shared data and meta-data to create business value. Privacy, transparency, auditing and control requirements in addition to regulation, place specific challenges to MaaS that need to be overcome in order to enable sustainable business value creation for stakeholders in the value chain. The latter is particularly evident within Europe [6], which is the context of this paper.

\subsection{MaaS}

The adoption of MaaS by the transport sector could introduce the potential of value creation for various stakeholders, although there is considerable dependency on the alignment of data strategies between organizations involved [13]. Introducing MaaS into the transport business ecosystem, to encompass both private and public transit, creates a new mode of transport that does not require the user to own their own vehicle. Autonomous and Connected Transport will generate new disruptive value propositions for each MaaS stakeholder: The User/Consumer (the human in the loop); the provider (service delivery); the ancillary service provider (e.g., insurance companies, advertisers, public authorities) and other stakeholders, i.e., environmental.

MaaS is a data-driven user-oriented paradigm which offers a unified ecosystem of available transportation options by leveraging different concepts including digitalization, personalized services, multimodality, on-demand access, real-time route planning, simplified payment with integrated services including information, planning, payment, and ticketing integration [14]. Sochor et al. [14] categorize MaaS levels from 0 to 4 based on the level of integration. An imperative requirement of integrated services is an open mobility ecosystem which promotes data accessibility. Data is a key asset in MaaS and sharing high-quality data between stakeholders can be complicated due to its business value, regulations, and concerns regarding data protection and privacy. Data analytics can reveal travel patterns so that supply and demand can be balanced with dynamically adapting routes and schedules. However, service providers can be reluctant to share data of their customer base, as is evident in the public transport sector. These specific data challenges for the MaaS business case can be addressed using DLT, such as blockchain, to provide scalable systems, fulfilling the needs of business value creation, while allowing degrees of control and transparency demanded of regulation that other potential solutions do not.

\subsection{Blockchain}

The decentralization, transparency, and immutability features of DLT have the potential to address some of the technical and legal challenges faced by MaaS. Some of these challenges can be listed as payment integration, developing trust for collaboration, and data sharing and access [15]. Smart contracts, that are defined in this paper as self-executing piece of code distributed through DLT, can define terms of agreements involving multiple parties and enforcing its performance. Smart contracts can invite various stakeholders such as end-users, service providers, insurance companies, operators, advertisers to promote the added value of MaaS. For example, insurance companies could bid for journey based micro-policies based on real time conditions including weather conditions, trip 
duration, route, and driver profile and the number of occupants. The execution of the micro-policy could be enacted through a smart contract with the choice of provider left up to the purchaser. Such DLT applications are not specific to MaaS, but are a powerful set of DLT capabilities (horizontal dimension) that can be applied to solving particular requirements in diverse situations including MaaS (vertical dimension).

\subsection{Opportunities and Challenges through the Integration of MaaS and DLT}

DLT can create opportunities for business value creation through three specific business activities: authentication, disintermediation and by reducing transaction costs [16]. The examples of blockchain and smart contracts in procurement and service delivery are increasing, pointing out emerging opportunities.

In addition, blockchain can address the core challenge of data protection and privacy for data centric MaaS business cases created by the introduction of the General Data Protection Regulation (GDPR) by the EU in 2018. GDPR requires users to be informed about the type of personal data to be collected and the specific purpose of its processing so that they can make an informed choice on granting consent. GDPR compliance requires an organization to guarantee accountability of internal procedures and to deploy appropriate technical and organizational security measures which challenges conventional systems underpinning current data centric business cases for MaaS.

For example, Zyskind et al. [17] demonstrate a blockchain system that allows users to control access and distribution of their data. Consent is implicit as the data cannot be accessed without the private cryptographic key of the owner. Access to the raw data is not allowed to third parties, and so prevents the copying and further distribution without the owner's consent, while providing processing operations over the data without direct access through zero knowledge proofs.

Such a permission based DLT can improve data protection and cybersecurity, since it provides a trust agnostic framework in the cross enterprise MaaS domain, by defining common rules, for example through smart contract capability $[18,19]$, for the stakeholders to comply with while improving transparency by rendering intermediaries unnecessary and eliminating them [20].

\section{Applying the Business Model Canvas to MaaS}

\subsection{Business Value}

All goods and services have some value, based on diverse value notions, namely exchange, intrinsic, sentimental or use value, offering a unique selling point to its providers, whilst satisfying a user need at the same time. This competitive advantage allows a firm (i.e., supplier) to maintain higher profit rate in comparison with the sector average and if maintained in the long-term becomes a sustainable competitive advantage [21,22].

Value chain analysis [23] has been the prominent analytical framework of traditional services for decades. However, since it was not developed to analyze data services, it does not serve equally well when analyzing contemporary data services such as MaaS. Thus, targeted alternative approaches are being developed, e.g., 'linked-data linear value chain' [24] or non-linear 'data value network' [25]. Nonetheless, there is limited consensus among academics and practitioners regarding the best approach to evaluate value creation through data generated by products and services in the 21st century.

The Business Model Canvas (BMC) has the Value Proposition at its core [26], so offers a suitable framework to analyse the value implications of DLT and blockchain for MaaS, given its previous use to evaluate new mobility services including within Living Lab conditions [27]. Further value generation alternatives have led to the evolution of advanced versions of the BMC, such as the Lean Canvas - LC [28] or the Ethics Canvas - EC [29] to deal with novel and disruptive emerging products and services, such as MaaS. In order to conduct an advanced evaluation of DLT and blockchain, this paper uses an integrated $\mathrm{BMC}+\mathrm{LC}+\mathrm{EC}$ canvas (Figure 1). Figure 1 presents MaaS value creation analyses for both existing incumbent enterprises and emerging disruptive and lean start-ups while 
overlaying the ethics and privacy requirements for businesses in the era of GDPR which can create additional value from MaaS.

\begin{tabular}{|c|c|c|c|c|c|c|}
\hline \multirow{2}{*}{$\begin{array}{l}\text { Key Partners: User/Consumer; } \\
\text { Service Delivery Provider; } \\
\text { Ancillary Service Provider; } \\
\text { Environment; blockchain and } \\
\text { smart contract developers; } \\
\text { business \& consumer groups } \\
\text { (Problem): Changing from } \\
\text { current use to MaaS; Trust \& } \\
\text { Privacy; Data, Service, } \\
\text { Payment and Infrastructure } \\
\text { Integration } \\
\text { (Existing Alternatives): Cash } \\
\text { and credit based human } \\
\text { driver transport; i.e. taxis, } \\
\text { bus, rail, plane } \\
\text { [Individuals Affected]: Drivers: } \\
\text { alternative income models; } \\
\text { Consumers: new service } \\
\text { value; trust; fraud } \\
\text { Service Providers: new } \\
\text { business and finance models; } \\
\text { Government: Open Data } \\
\text { Environment: reduced } \\
\text { pollution; sustainability }\end{array}$} & $\begin{array}{l}\text { Key Activities: data } \\
\text { infrastructure, mining nodes, } \\
\text { mobile communications, } \\
\text { (Solution): Use blockchain \& } \\
\text { Smart Contracts } \\
\text { More efficient, transport with } \\
\text { increased ease of use and } \\
\text { stakeholder value and trust } \\
\text { [Behaviour] sustainable } \\
\text { energy, transparency, lock-out }\end{array}$ & \multirow{2}{*}{\multicolumn{2}{|c|}{$\begin{array}{l}\text { Value Proposition: online real- } \\
\text { time access to Individual } \\
\text { customer on-demand service } \\
\text { requests } \\
\text { (Unique Value Proposition): } \\
\text { Cross service integrated } \\
\text { marketplace for transport } \\
\text { using smart contracts and } \\
\text { blockchain. } \\
\text { (High Level Concept): Smart } \\
\text { Contract and Blockchain } \\
\text { based MaaS provides secure, } \\
\text { transparent, immutable } \\
\text { supporting real-time, on- } \\
\text { demand transport services to } \\
\text { create increased value for } \\
\text { business, personal, societal } \\
\text { and environmental } \\
\text { stakeholders. } \\
\text { [What Can We Do?]: Provision } \\
\text { for fair access; Transparency } \\
\text { for all stakeholders while } \\
\text { ensuring privacy; } \\
\text { Environmental sustainability } \\
\text { for mining energy. }\end{array}$}} & \multicolumn{2}{|c|}{$\begin{array}{l}\text { Customer Relationships: } \\
\text { On-demand transport } \\
\text { services; holistic service offers } \\
\text { (Unfair Advantage): Smart } \\
\text { contracts payment integration } \\
\text { without the cost of single } \\
\text { ticketing systems. } \\
\text { [Worldviews]: Participants in } \\
\text { MaaS can feel that they have } \\
\text { made a contribution to better } \\
\text { and more sustainable urban } \\
\text { living with a global impact. }\end{array}$} & \multirow{2}{*}{$\begin{array}{l}\text { Customer Segments: B2B, B2C } \\
\text { and government agencies. } \\
\text { Blockchain and Smart } \\
\text { Contracts will enable a cross } \\
\text { service integrated } \\
\text { marketplace with aggregate } \\
\text { and discrete data transaction } \\
\text { capability for all stakeholders. } \\
\\
\text { (Early Adopters): B2C :- Users } \\
\text { with access to digital paymen } \\
\text { systems and requiring on- } \\
\text { demand transport. } \\
\text { B2B :- disruptive business } \\
\text { seeking to offer automatic on } \\
\text { demand service offerings } \\
\text { [Groups Affected]: Transport } \\
\text { users; Unions; Societal groups } \\
\text { - pensioners, youth (<18); } \\
\text { Unemployed; Self employed; } \\
\text { Legal; Financial; Accounting. }\end{array}$} \\
\hline & $\begin{array}{l}\text { Key resources: distributed } \\
\text { nodes for mining efficiency; } \\
\text { mobile communications } \\
\text { infrastructure and capacity. } \\
\text { (Key Metrics): \#Users; \#Smart } \\
\text { Contracts; \#Smart contract } \\
\text { value growth; blockchain } \\
\text { latency } \\
\text { [Relations]; trust; blockchain } \\
\text { adoption; user/commercial } \\
\text { inertia; fraud }\end{array}$ & & & \multicolumn{2}{|c|}{$\begin{array}{l}\text { Channels: B2C:- advertising - } \\
\text { online, broadcast and } \\
\text { physical; tax incentives } \\
\text { B2B :- employer subscription; } \\
\text { industry and sector trade } \\
\text { shows } \\
\text { [Group Conflicts] Reduced } \\
\text { Union/Worker influence; } \\
\text { Exclusion of older population } \\
\text { with little or no digital access; } \\
\text { Exclusion of youth with no } \\
\text { ability to grant consent }\end{array}$} & \\
\hline \multicolumn{3}{|c|}{$\begin{array}{ll}\text { Cost Structure: cost sharing in charges } & \text { [Product or Service Failure]: Fraud, } \\
\text { for block verification (mining) to make } & \text { denial of service; service lock out; } \\
\text { mining attractive to investors; Cost } & \text { lack of open access for all; } \\
\text { sharing in communications to ensure } & \text { Communications failure may lead to } \\
\text { adequate bandwidth for consumers to } & \text { transport service stopping. } \\
\text { access services. } & \end{array}$} & \multicolumn{2}{|c|}{$\begin{array}{l}\text { Revenue Model: subscription to real- } \\
\text { time on-demand services; } \\
\text { Value sharing from Advertising; spot- } \\
\text { bidding i.e. insurance and advertising } \\
\text { Value add services to open Data; } \\
\text { Smart contract value sharing. }\end{array}$} & \multicolumn{2}{|c|}{$\begin{array}{l}\text { [Problematic Use of Resources]: Block } \\
\text { mining uses a large amount of } \\
\text { energy, need to ensure energy } \\
\text { sources are sustainable for this and } \\
\text { other aspects of the business } \\
\text { model. } \\
\text { High on-demand may lead to } \\
\text { higher congestion }\end{array}$} \\
\hline
\end{tabular}

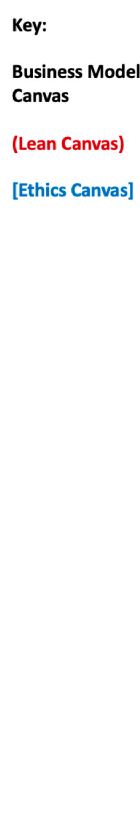

Figure 1. A combined BMC + LC + EC application for MaaS-Authors' analysis.

\subsection{An Integrated Approach for MaaS}

As outlined in Figure 1, a core value proposition derives from the ability for MaaS operators to offer online real-time access to MaaS system users, either on demand or based on service design features. In this section the focus is on blockchain as a specific DLT application, given their unique feature to generate the opportunity with smart contracts for a trusted cross-service marketplace. Such a marketplace is an innovative new offering and could be created in a multitude of ways depending on local arrangements and stakeholders' vision.

Based on this integrated canvas (Figure 1), this paper highlights the considerable new scope for existing business models, the emergence of new disruptive business models, as well as the potential wider societal impacts of the use of blockchain for MaaS. When reviewing the customer segments, service adopters and groups affected, it becomes apparent that fundamental ethical challenges arise which need to be evaluated in more detail in the future, particularly in the context of GDPR. Nevertheless, the key finding through this analysis is the major role of data for all three dimensions. The significance of posing questions such as:

- What is the data in this business ecosystem?

- Who generates data in this business ecosystem?

- Where is data transferred to and from in this business ecosystem?

- How is business ecosystem data used?

- How can data use be transparent to all business ecosystem stakeholders?

The integrated canvas can be used to interrogate different value scenarios highlighting opportunities and challenges for example in the data flow interaction between actors, enterprises and stakeholders as explained Figure 2 below.

The types and flow of data is illustrated through the travel overview of a given system user (Figure 2). Blockchain and smart contracts can enhance transactional aspects, increasing trust between business eco-system and network actors. Given that data can be confined to the digital environment or also be linked with the physical environment, they become an integral component of an individual's digital identity. Data generation is associated with a digital identity or actor. Data 
transaction involves a transfer activity of an entity between actors. Each of these elements (Actor, Entity and Activity) are the key component classes of a provenance system [30]. As a transactional system, blockchain is open and queryable, Actors are identifiable by their public keys and transactions between them are validated by timestamped blocks. In this way transparency is enabled and provenance of digital assets, namely data, can be observed and registered.

Consequently, data are at the nucleus of any business data model, such as blockchain for MaaS, which is characterized by data transfers between Actors, which can be either individuals or organizations. The model (Figure 2) used in this paper depicts data types and data transfers based on a routine day of a typical urban persona. The aim is to identify the public or private stakeholders who would have an interest in using these data types and the ways in which they may capitalize on these data types to generate value and build a sustainable competitive advantage.

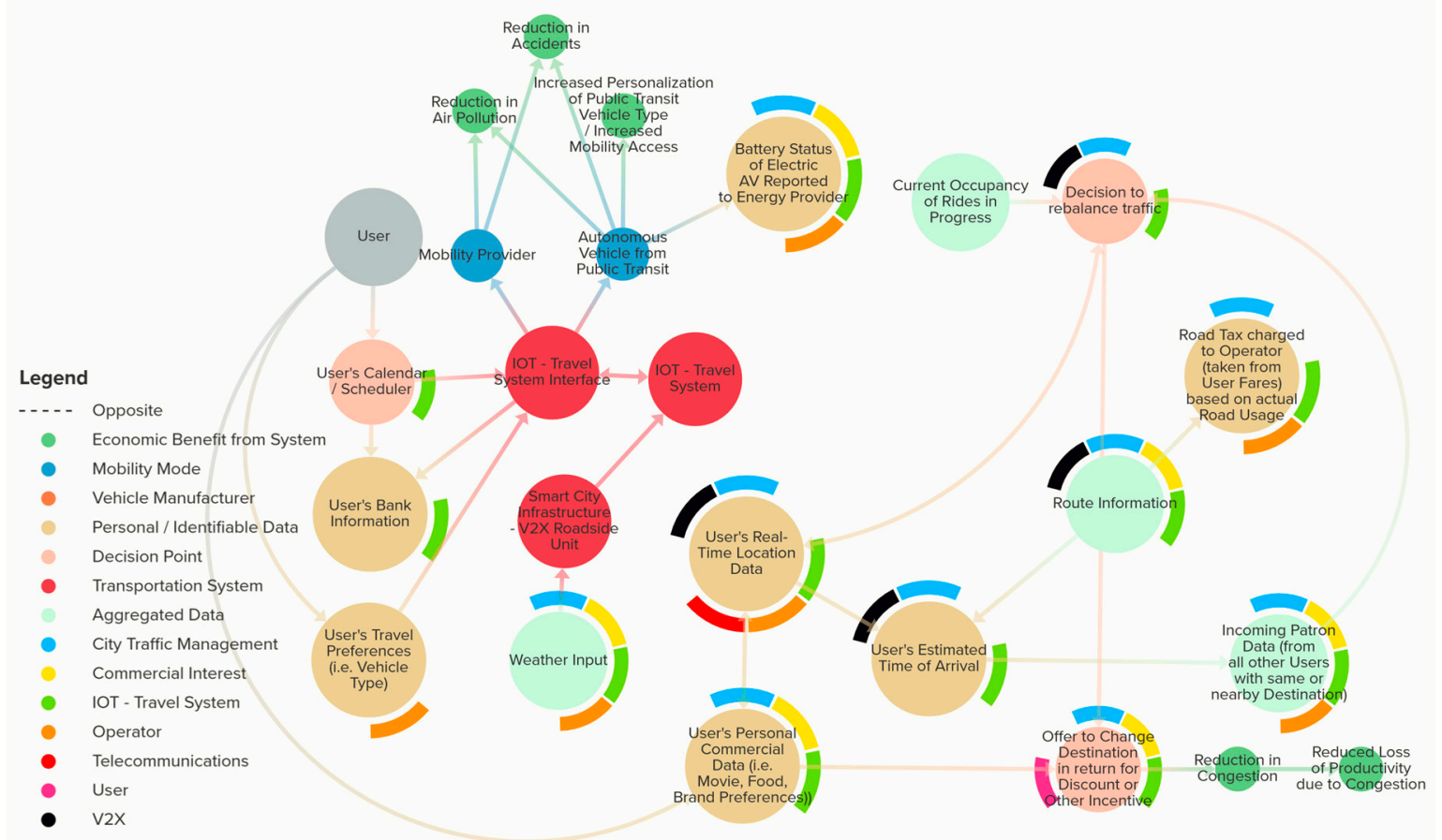

Figure 2. Overview of an individual's blockchain based data types and flows among MaaS stakeholders-Authors' analysis.

To explore the improvement blockchain integration can offer to a MaaS system, compared to a traditional MaaS, the utilization of the user's personal commercial data, that are defined as any transactable digital assets that can be used to create business value, is presented as an example. The benefits of including data about the user's personal commercial preferences in a MaaS system are manifold and benefit:

- the traffic system by attempting to divert traffic from congested parts of the network;

- the user by offering alternative destinations based on his specific personal preferences;

- commercial partners of the MaaS system (which can be e.g., restaurants, movie theaters, retail stores), by offering them an innovative targeted means of promoting their business.

An example utilization of a user's personal commercial data is visualized in Figure 3.

In a traditional MaaS system, the user would have to trust an intermediary with their data. The intermediary stores the user's data in their database system and distributes the relevant data to the commercial nodes of the MaaS system that require it and have permission to access it. Of course, the data handling intermediary has the user's consent to use and share their data; though often, the users are requested to provide consent for a wide variety of purposes at once, leaving many opportunities for unsanctioned use of that data. At the same time, all commercial partners of the MaaS system need 
to trust the intermediary to properly handle their data and promote their business to an optimally selected group, so that the system can operate unhindered [31].

In a blockchain-based MaaS system, the users can have more control over who has access to their preferences and get alternative destination suggestions that are better suited to them. At the same time, the commercial partners do not need to trust data handling, advertising intermediaries but can promote their services, to a more efficiently selected target group in a decentralized manner. Due to the removal of the 'middle-man' from the targeted advertisement system, this will also allow the users to get increased reciprocal benefits for sharing their data [32]. This decentralized data allocation would offer to both users and commercial partners of the system better supervision of how their personal data is used, and who has access to them, as well as increased security from cyber-attacks compared to traditional systems [33].

Figure 3 offers an overview of a generic set of journeys on a recreational evening out for an imaginary persona: Mike. Utilizing Mike's personal and commercial data, the MaaS based blockchain system makes suggestions about transport mode, location choice, movie selection, beverage preferences, including a friend who joins Mike this evening. Mike's allergies are taken into account regarding both vehicle and beverage suggestion. Movie and location suggestions are also based on traffic and network conditions which are shared across the MaaS platform. The way Mike's Personal Commercial Data are transferred from and to other adjacent data nodes of the MaaS system is outlined in this Figure 3 snapshot.
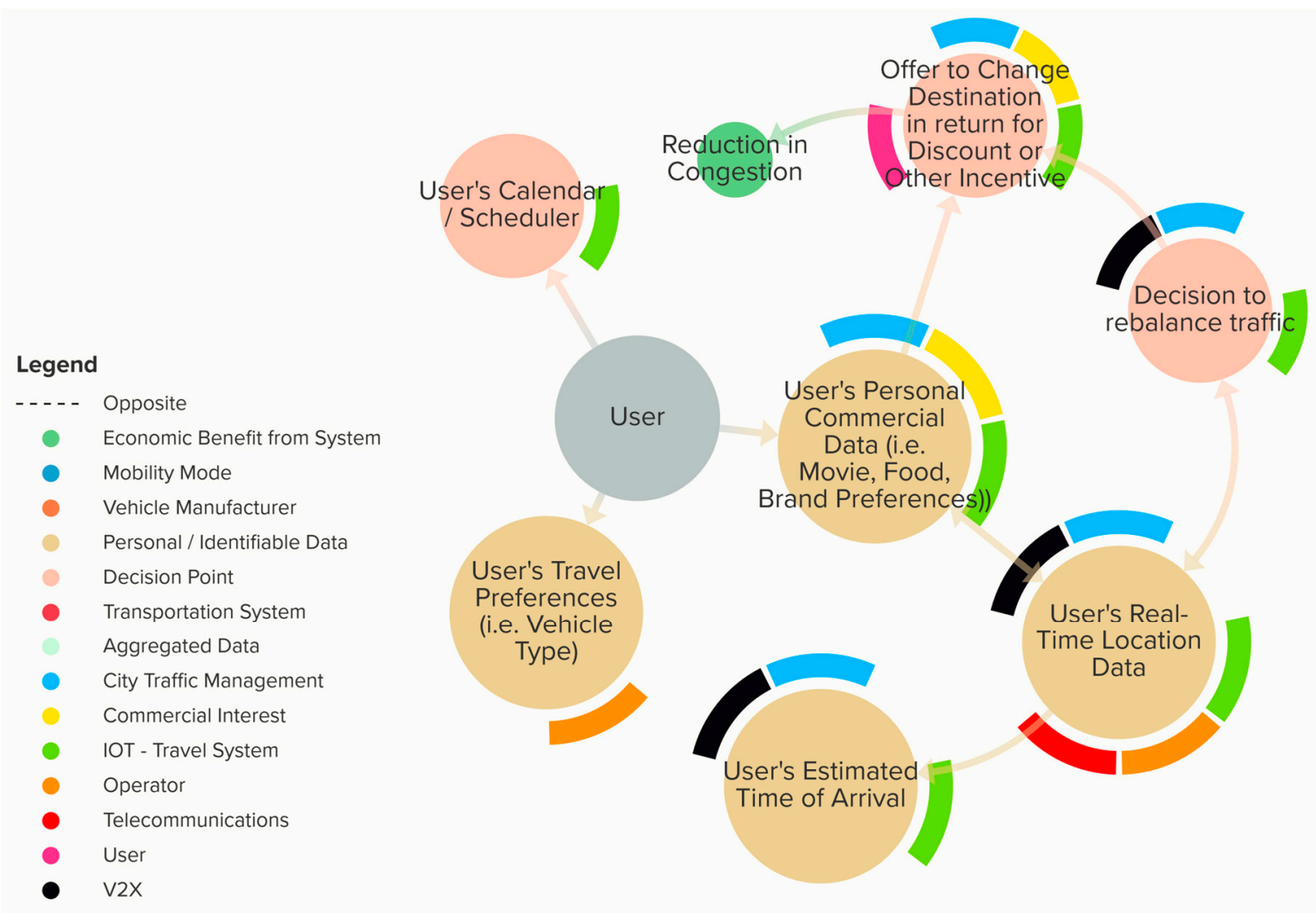

Figure 3. Overview of an individual's blockchain based data types and flows that make use of their Personal Commercial Data-Authors' analysis focusing on a subset of Figure 2.

\subsection{Combining Blockchain and MaaS}

Starting from already operating similar MaaS applications (e.g., in Helsinki), the user may request through a blockchain based MaaS system to plan one's journey to a cultural venue for the same evening. Aside from the obvious business benefits for transport providers serving users on such a MaaS system, local authorities may also benefit by such a system by collecting information about congestion, road condition, infrastructure operations. The innovation introduced by blockchain or 
other DLT in this case is that each piece of information could be automatically attributed to that specific user, acknowledging one's contribution to the system.

Thus, two types of datasets co-exist concurrently within the system:

1. Personally identifiable data

2. Aggregate data

Combining these two types of user data with real-time location information could be beneficial for both individuals and the transport network overall. Using incentives customized according to user current activity and journey destination, it is possible to introduce wider system benefits via better informed mobility planning and management. Slowing down, e.g., by $2 \mathrm{~km} / \mathrm{h}$ a fleet of vehicles at a given location or holding another fleet of vehicles for an additional 4 seconds at a traffic light, may offer augmented system level benefits. Value through such services will be created through improved operations management for specific actors within selected sectors e.g., hospitality, recreation. As already hinted in the literature [34,35], autonomous vehicles (AV) may maximize the potential of such benefits, both at individual and system levels. DLT can ensure a decentralized, immutable and reliable system which would increase business value at aggregate level, but also user value at an individual level.

\section{Evaluation \& Next Steps}

After outlining the potential operation of a blockchain based MaaS to create value for both users and the business ecosystem, it is essential to evaluate such a mobility system. This evaluation is based on a generic SWOT analysis, where the imminent and long-term opportunities and threats are presented in this section.

\subsection{Imminent}

- The major strength offered through a DLT based MaaS is having a more transparent and impartial operation interface, attracting more early adopters. This overcomes barriers faced by existing operators where it is unclear how, when and why options by certain mobility providers are offered to a given user and not to others.

- Identifying the optimal level of incentives by transport mode, socio-economic group or geographic location is an important opportunity to motivate users to offer their journey and preference data. Additional key considerations are also incentive headway and types (e.g., discounts, free services).

- Establishing the required infrastructure for a blockchain based MaaS to be introduced is a key weakness, not only due to the capital needs, but also due to the technological requirements of such an initiative. Conducting small scale trials in the short-term, particularly in the tourism and hospitality sectors, could be an option to build critical mass locally and address fundamental blockchain disadvantages [36].

- Data protection and data management compliance at local, national and international levels are naturally an immediate threat. DLT is currently restricted by GDPR provisions within the EU [20], such as the qualification of the data owner (i.e., data miner) as Data Processor (Article 4), the virtually impossible implementation of the Right to erasure (Article 17) at least for permission based DLT, or the general prohibition of automatic decision making (Article 22), which hampers data processing through smart contracts.

\subsection{Long-Term}

- The main long-term threat of a blockchain based MaaS is the compliance and compatibility of any public or permission based DLT with data protection regulations e.g., GDPR. It is auspicious that the EU could enact a detailed regulation to specify the criteria of assessment for the 'compatible purpose' of data processing provided in Article 6(4) GDPR or, at least, overhaul current ethical guidelines, still based on WP 203, adopted on 2 April 2013 [37]. 
- An intertwined weakness of the proposed system is the reaction in case of the collapse of an operator of a blockchain based MaaS system. Defining data ownership and liability is crucial, particularly due to previous examples and the yet non-proven business models of emerging transport operators (e.g., Uber, Lyft).

- The ultimate strength of a DLT based MaaS system is the potential to progress from competition to collaboration, at least locally. Utilizing the decentralized and immutable DLT features, would address one of the major challenges of MaaS currently i.e., trusting an intermediary acting as a system operator [38].

\section{Conclusions}

DLT has introduced an array of opportunities at a range of applications worldwide. Nevertheless, these opportunities are entangled with a range of challenges. This paper combines two contemporary technological innovations to introduce the notion of a DLT based MaaS using blockchain in particular. By employing an integrated version of the Business Model Canvas (Figure 1) and by outlining data flows between the numerous system stakeholders (Figure 2), it underlines the potential benefits of such a system which would increase trust among stakeholders. The overall aim has been to identify where and how business value is created through data-based services.

However, as discussed in Section 4, a DLT based MaaS would not be a panacea by default. A series of weaknesses and challenges would need to be addressed before a wide use of such a solution. Data protection, data access, user privacy, infrastructure needs and competition management all pose critical challenges which should not be neglected by any stakeholder [6]. Local trials or Living Lab testing within restricted environments e.g., at the European Commission JRC or tourist destinations, could offer valuable insight, building required capacity.

Despite the limitations of this paper which is based solely on a single scenario of Mike, future research could enhance this by using diverse user types and travel scenarios based on existing literature. Additionally, it is important to explore the regulatory, legal and ethical compatibility of DLT with MaaS to ensure that digital divide exclusion is minimized and under which conditions are data sharing market options feasible to create business value. It is indisputable though that this is a topic which requires multi-disciplinary approaches, and which will continue to attract interest by practitioners and academics globally.

Author Contributions: Conceptualization, G.H., S.D., I.F.S., I.F., Q.F., M.E., F.C. and N.T.; methodology, G.H., S.D., F.C. and N.T.; investigation, G.H., I.F.S. and F.C.; resources, G.H., I.F.S., F.C. and N.T.; writing-original draft preparation, G.H., S.D., I.F.S., I.F., Q.F., F.C. and N.T.; writing-review and editing, G.H., S.D., I.F.S., I.F., Q.F., E.M., F.C. and N.T.; visualization, G.H., S.D. and I.F.; supervision, I.F.S., I.F. and N.T.; project administration, I.F.S., I.F. and N.T.

Funding: This publication has emanated from research supported in part by a research Grant from Science Foundation Ireland under Grant Number 13/RC/2106 and 17/SP/5447.

Acknowledgments: This paper was conceptualized and launched by work conducted during the $1^{\text {st }}$ WISE-ACT Training School, so the authors acknowledge the support of the WISE-ACT CA16222 COST Action.

Conflicts of Interest: The authors declare no conflict of interest. The funders had no role in the design of the study; in the collection, analyses, or interpretation of data; in the writing of the manuscript, or in the decision to publish the results.

\section{References}

1. Harari, Y.N. 21 Lessons for the 21st Century; Spiegel \& Grau: New York, NY, USA, 2018.

2. Rennock, M.J.W.; Cohn, A.; Butcher, J.R. Blockchain Technology and Regulatory Investigations. Pract. Law Litig. 2018, 2, 35-44.

3. Juniper Research. Smart Citie -What's in It for Citizens? 2018. Available online: https://newsroom.intel.com/wp-content/uploads/sites/11/2018/03/smart-cities-whats-in-it-for-citizens.pdf (accessed on 25 July 2019).

4. Floridi, L. Big Data and Their Epistemological Challenge. Philos. Technol. 2012, 25, 435-437. 
5. Thomopoulos, N.; Givoni, M.; Rietveld, P. ICT for Transport: Opportunities and Threats; Edward Elgar: Cheltenham, UK, 2015.

6. Zmud, J.; Reed, N. White Paper: Synthesis of the Socio-Economic Impacts of Connected and Automated Vehicles and Shared Mobility. In Proceedings of the 6th EU-US Symposium, Brussels, Belgium, 26-27 June 2018.

7. Higgins, E.T. Making a good decision: Value from fit. Am. Psychol. 2000, 55, 1217-1230.

8. Hoppe, M.; Christ, A.; Castro, A.; Winter, M.; Seppänen, T.-M. Transformation in transportation? Eur. J. Future Res. 2014, 2. doi:10.1007/s40309-014-0045-6.

9. Rode, P.; Floater, G.; Thomopoulos, N.; Docherty, J.; Schwinger, P.; Mahendra, A.; Fang, W. Accessibility in Cities: Transport and Urban Form. In Disrupting Mobility; Springer: Cham, Switzerland, 2017; pp. 239273.

10. Silva, B.N.; Khan, M.; Han, K. Towards sustainable smart cities: A review of trends, architectures, components, and open challenges in smart cities. Sustain. Cities Soc. 2018, 38, 697-713.

11. Thomopoulos, N.; Nikitas, A. Smart Urban Mobility Futures: Editorial for Special Issue. Int. J. Automot. Technol. Manag. 2019, 19, 1-9.

12. Karjalainen, P. Incorporating Autonomous and Connected Transport into MaaS. In Proceedings of the WISE-ACT 2nd Workshop 2018, Budapest, Hungary, 21-22 November 2018.

13. Costantini, F.; Archetti, E.; Di Ciommo, F.; Ferencz, B. IoT, intelligent transport systems and MaaS (mobility as a service). In Proceedings of the 22nd International Legal Informatics Symposium IRIS 2019, Salzburg, Weblaw, 21-23 February 2019; pp. 245-254.

14. Sochor, J.; Arby, H.; Karlsson, I.C.M.A.; Sarasini, S. A topological approach to Mobility as a Service: A proposed tool for understanding requirements and effects, and for aiding the integration of societal goals. Res. Transp. Bus. Manag. 2018, 27, 3-14.

15. MaaS Alliance. Main Challenges Associated with MaaS \& Approaches for Overcoming Them. 2019. Available online: https:/maas-alliance.eu/wp-content/uploads/sites/7/2019/02/Main-challenges-pdf.pdf (accessed on 25 July 2019).

16. Nowiński, W.; Kozma, M. How Can Blockchain Technology Disrupt the Existing Business Models? Entrep. Bus. Econ. Rev. 2017, 5, 173-188.

17. Zyskind, G.; Nathan, O.; Pentland, A.S. Decentralizing privacy: Using blockchain to protect personal data. In Proceedings of the 2015 IEEE Security and Privacy Workshops, San Jose, CA, USA, 21-22 May 2015; pp. 180-184.

18. De Filippi, P.; Wright, A. Blockchain and the Law. The Rule of Code; Harvard University Press: Cambridge, MA, USA, 2018; ISBN 9780674976429.

19. Wiatrowski, A. Blockchain Technology-A Threat or a Solution for Data Protection? Jusletter IT of 22 February, 2018. Available online: https://jusletter-it.weblaw.ch/en/issues/2018/IRIS/blockchaintechnolog_96aad6c440.html_ONCE\&login=false (accessed on 25 July 2019).

20. European Commission. 2018 Reform of EU Data Protection Rules; European Commission: Brussels, Belgium, 2018.

21. Bowman, C.; Ambrosini, V. Value creation versus value capture: Towards a coherent definition of value in strategy. Br. J. Manag. 2000, 11, 1-15.

22. Stabell, C.B.; Fjeldstad, Ø.D. Configuring value for competitive advantage: on chains, shops, and networks. Strateg. Manag. J. 1998, 19, 413-437.

23. Porter, M.E. The Competitive Advantage: Creating and Sustaining Superior Performance; Free Press: New York, NY, USA, 1985.

24. Latif, A.; Saeed, A.U.; Hoefler, P.; Stocker, A.; Wagner, C. The Linked Data Value Chain: A Lightweight Model for Business Engineers. In Proceedings of I-KNOW'09 and I-SEMANTICS '09, Graz, Austria, 2-4 September 2009.

25. Attard, J.; Orlandi, F.; Auer, S. Exploiting the Value of Data through Data Value Networks. In Proceedings of the 10th International Conference on Theory and Practice of Electronic Governance-ICEGOV '17; ACM Press: New York, NY, USA, 2017; pp. 475-484.

26. Osterwalder, P.\& al. Business Model Generation; John Wiley \& Sons, Inc.: Hoboken, NJ, USA, 2010.

27. Hjalmarsson, A.; Thomopoulos, N.; Hodgson, F.; Klok, E.; Bjilsma, M.; Dethmers, V. D5.3 Business Aspects, Sustainable Social Networking Services for Transport (SUNSET) Deliverable, FP7 No. 270228. 2012. 
Available online: http://www.sunset-project.eu/pdf/SUNSET_D5.3_Business_Aspects.pdf (accessed on accessed on 31 July 2012).

28. Maurya, A. Running Lean: Iterate from Plan A to a Plan That Works; 2nd ed.; O'Reilly Media: Newton, MA, USA, 2012; ISBN 1449305172.

29. Reijers, W.; Koidl, K.; Lewis, D.; Pandit, H.J.; Gordijn, B. Discussing Ethical Impacts in Research and Innovation: The Ethics Canvas. In Proceedings of the IFIP International Conference on Human Choice and Computers, Poznan, Poland, 19-21 September 2018; pp. 299-313.

30. Lebo, T.; Sahoo, S.; McGuinness, D.; Belhajjame, K.; Cheney, J.; Corsar, D.; Garijo, D.; Soiland-Reyes, S.; Zednik, S.; Zhao, J. PROV-O: The PROV Ontology; W3C Recommendation, World Wide Web Consortium: Geneva, Switzerland, 2013. Available online: https://www.w3.org/TR/prov-o/ (accessed on 25 July 2019).

31. Chowdhury, M.J.M.; Colman, A.; Kabir, M.A.; Han, J.; Sarda, P. Blockchain Versus Database: A Critical Analysis. In Proceedings of the 2018 17th IEEE International Conference On Trust, Security And Privacy In Computing And Communications/12th IEEE International Conference On Big Data Science And Engineering (TrustCom/BigDataSE), New York, NY, USA, 1-2 August 2018; pp. 1348-1353.

32. Contentos. The Decentralized Global Content Ecosystem-White Paper. 2019. Available online: https://www.contentos.io/subject/home/pdfs/white_paper_en.pdf (accessed on 18 September 2019).

33. Zheng, Z.; Xie, S.; Dai, H.-N.; Chen, X.; Wang, H. Blockchain Challenges and Opportunities: A Survey Shaoan Xie Hong-Ning Dai Huaimin Wang. Int. J. Web Grid Serv. 2017, 14, 1-24.

34. Cohen, S.A.; Hopkins, D. Autonomous vehicles and the future of urban tourism. Ann. Tour. Res. 2019, 74, $33-42$.

35. Thomopoulos, N.; Givoni, M. The autonomous car-A blessing or a curse for the future of low carbon mobility? An exploration of likely vs. desirable outcomes. Eur. J. Futur. Res. 2015, 3, 14.

36. Gatteschi, V.; Lamberti, F.; Demartini, C.; Pranteda, C.; Santamaria, V. To Blockchain or Not to Blockchain: That Is the Question. IT Prof. 2018, 20, 62-74.

37. European Commission Opinion 03/2013 on Purpose Limitation; European Commission: Brussels, Belgium, 2013. Available online: https:/ec.europa.eu/justice/article-29/documentation/opinionrecommendation/files/2013/wp203_en.pdf (accessed on 25 July 2019).

38. Nguyen, T.H.; Partala, J.; Pirttikangas, S. Blockchain-based Mobility-as-a-Service. In Proceedings of the 28th International Conference on Computer Communications and Networks (ICCCN 2019), Valencia, Spain, 29 July 29-1 August 2019.

(C) 2019 by the authors. Licensee MDPI, Basel, Switzerland. This article is an open access article distributed under the terms and conditions of the Creative Commons Attribution (CC BY) license (http://creativecommons.org/licenses/by/4.0/). 